SLA-74-0080

Potent-Gation
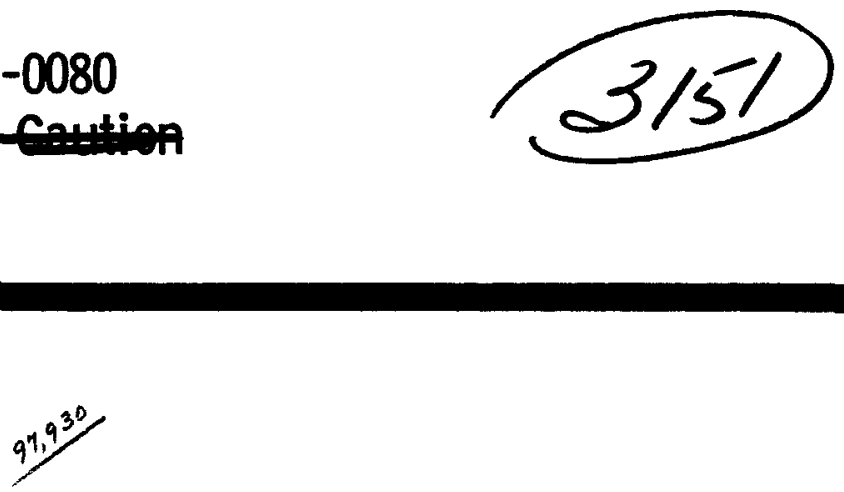

ANALYSIS OF FAST RISETIME PULSED

THERMOELECTRIC GENERATOR

E. L. Burgess

Sandia Laboratories 


\section{DISCLAIMER}

This report was prepared as an account of work sponsored by an agency of the United States Government. Neither the United States Government nor any agency Thereof, nor any of their employees, makes any warranty, express or implied, or assumes any legal liability or responsibility for the accuracy, completeness, or usefulness of any information, apparatus, product, or process disclosed, or represents that its use would not infringe privately owned rights. Reference herein to any specific commercial product, process, or service by trade name, trademark, manufacturer, or otherwise does not necessarily constitute or imply its endorsement, recommendation, or favoring by the United States Government or any agency thereof. The views and opinions of authors expressed herein do not necessarily state or reflect those of the United States Government or any agency thereof. 


\section{DISCLAIMER}

Portions of this document may be illegible in electronic image products. Images are produced from the best available original document. 
Issued by Sendia Laboratories, operated for the United States Atomic Energy Commission by Sandia Corporation.

\section{NOTICE}

This report was prepared as an account of work sponsored by the United States Government. Neither the United States nor the United States Atomic Energy Commission, nor any of their employees, nor any of their contractors, subcontractors, or their employees, makes any warranty, express or implied, or assumes any legal liability or responsibility for the accuracy, completeness or usefulness of any information, apparatus, product or process disclosed, or represents that its use would not infringe privately owned rights.

SF 1004-DF(2-7A) 


\title{
PATENT CAUTION
}

SIA-74-0080

ANALYSIS OF FAST RISETTME PULSED

THERMOELECTRIC GENERATOR

\author{
E. L. Burgess
}

Electrical Transport Division 5155

Sandia Laboratories, Albuquerque, NM 87115

April 1974

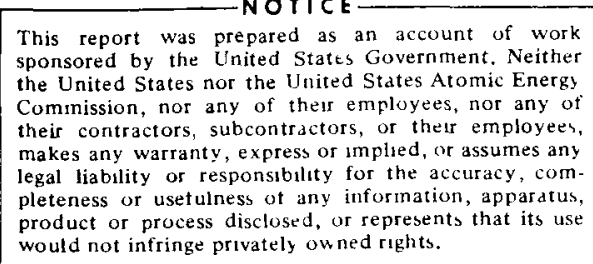

ABSTRACT

A pulsed thermoelectric generator which is heated by fissioning of U35 when exposed to a pulse of neutron irradiation is discussed. The open circuit voltage response of the device is determined using the CINDA numerical differencing analyzer computer code. A parametric study of material properties affecting system response is performed.

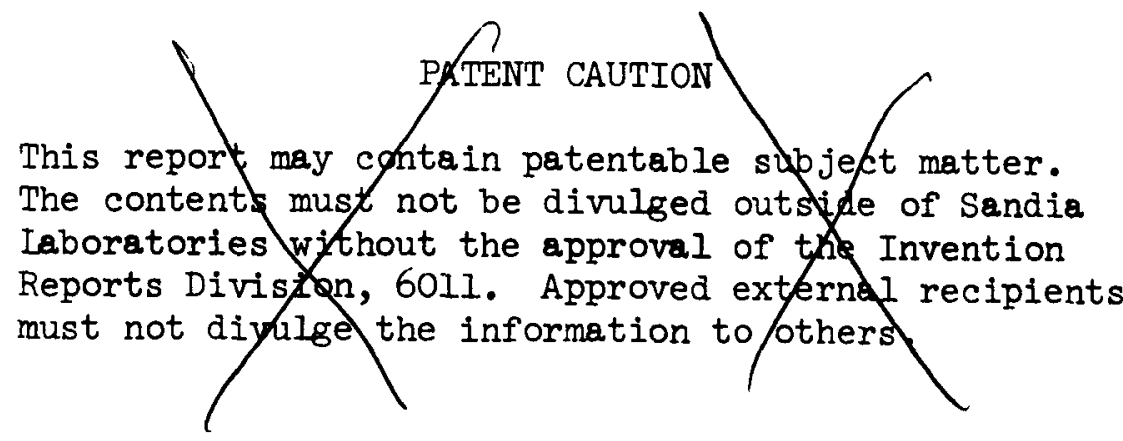




\section{Introduction}

Fast-response miniature neutron flux monitors have been developed at the Ios Alamos Scientific Laboratory using the thermoelectric effect of two dissimilar metals.1 The devices, called fission couples, are basically thermocouples whth a bead of fissionable material forming the actual junction between the two dissimilar metals of the thermocouple. Upon exposure to a pulse of neutrons the fissile bead is heated and the thermocouple produces an output voltage proportional to the integral neutron flux. The technique arose with the requirement to measure the temperature-time history of fissile materials under intense pulsed neutron irradiation.

This paper deals with extending the principle of the fission couples to a device which could produce useful electrical energy when exposed to pulsed neutron irradiation. The device as envisioned would take on the configuration depicted in Fig. 1. A simple thermocouple would consist of a disk of fissionable material, e.g., enriched uranium (U235), placed between disks of dissimilar thermoelectric materials. Several of these fission couples would be stacked in series electrically so as to produce the desired output voltage. To improve the performance of the device the thermoelectric materials would be $\mathrm{n}$ and p-type semiconductors selected for their high thermoelectric figure of merit, e.g., silicon-germanium alloys (SiGe).

When the device is subjected to a pulse of neutrons the $U^{235}$ is heated by fissioning and a temperature gradient is developed across each disk of thermoelectric material. A Seebeck voltage is developed which is proportional to the temperature gradient. The total device voltage, equal to the sum of the individual couple voltages, drives current through the external load. The generated voltage persists until the neutron flux ceases or until 
the temperature gradient is reduced to zero due to conduction of the heat from the $U^{235}$ through the thermoelectric material.

A pulsed generator of this type was first considered by Whitcomb ${ }^{3}$ but he dismissed the idea as being impractical due to an error in logic. He desired the device to respond to a very fast risetime ( nanoseconds) pulse of neutrons and concluded that it could not based on the transient thermoelectric analysis of Gray.4 Gray derived a characterlatic time for decay of transients caused by perturbations in the steady state operating conditions of a thermoelectric device. This characteristic time is related to the thermoelectric material parameters by the expression

$$
\tau=\rho c l^{2} / k
$$

where $\rho$ is the density $\left(\mathrm{gm} \mathrm{cm}^{-3}\right), c$ is the heat capacity (cal $\mathrm{gm}^{-1} \mathrm{o}^{-1}$ ), $\ell$ is the length $(\mathrm{cm})$, and $k$ is the thermal conductivity (cal $\sec ^{-1} \mathrm{~cm}^{-1}{ }^{0} \mathrm{~K}^{-1}$ ) of the thermoelectric elements. Whitcomb ${ }^{3}$ interpreted this characteristic time as the risetime and using typical values for material properties determined that the element thickness would have to be of the order of a few hundred to a few thousand angstroms for the device to respond on a nanosecond time scale. This thickness would have been impossible to obtain with the thermoelectric technology current at that time.

The error in Whitcomb's logic was assuming that Gray's characteristic time could also be interpreted as risetime. In the pulsed device the steady state condition is zero output or no temperature gradient across the thermoelectric elements. The pulse of neutrons causing heating in the $U^{235}$ corresponds to the transient or perturbation in the steady state condition. Hence the characteristic time would correspond to the time required to conduct the heat away from the $U^{235}$, reducing the temperature gradient to zero and 
returning the device to the steady state condition of zero output. With this interpretation it becomes obvious that long characteristic times are not detrimental to fast risetime response. In fact we will show that the optimum response is obtained when the heat conduction away from the $U^{235}$ is zero. This corresponds to zero thermal conductivity of the thermoelectric material and hence an infinite characteristic time.

In this paper the response of the pulsed thermoelectric device is investigated analytically. Several factors affecting the risetime and magnitude of the output voltage are considered. Experiments using the Sandia pulsed reactor (SPR-II) and designed to prove the principle of the device are described in a companion report. 5

\section{BASIC EQUATIONS}

Since the devlce of Fig. 1 consists of a stack of $\mathrm{N}$ fission couples the analysis can be performed on a single couple as shown in Fig. 2a. The total output voltage would equal $\mathrm{N}$ times the single couple voltage and the total output current would equal the single couple current since the couples are connected in series electrically. The thermal losses would be slightly different for the end elements but the effect on the total output will be small if $N$ is large (e.g. $N \geq 10)$. The equations are simplified if the absolute magnitude of the parameter values for the $n$ and $p$-type materials are equal. This is approximately true for SiGe alloys and hence the analysis becomes symmetrical about the center line of the $U^{235}$ disk. We need to analyze only one-half of a couple as shown in Fig. $2 b$.

The heat generated in the $\mathrm{U}^{35}$ is given by

$$
\dot{q}=E_{f^{N}} \bar{\sigma}_{f} \varphi(t)
$$


where $E_{f}$ is the average energy per fission $\left(=6.88 \times 10^{-12}\right.$ cal for $\left.U^{235}\right)$, $\mathrm{N}_{f}$ is the density of fissionable nuclei $\left(\mathrm{cm}^{-3}\right), \bar{\sigma}_{f}$ is the effective fission cross-section $\left(=1.25 \times 10^{-24} \mathrm{~cm}^{2}\right.$ for $\left.U^{35}\right)$, and $\varphi(t)$ is the neutron flux $\left(\mathrm{cm}^{-2} \mathrm{sec}^{-1}\right)$. The temperature at any time and position in the U $^{235}$ (Region 1) is determined from the equation

$$
\rho_{1} C_{1} \frac{\partial T_{1}}{\partial t}=\frac{\partial}{\partial x}\left(k_{1} \frac{\partial T_{1}}{\partial x}\right)+\dot{q}+0.239 j^{2} r_{1}
$$

The temperature in the SiGe (Region 2) is determined from the equation

$$
\rho_{2} \mathrm{C}_{2} \frac{\partial \mathrm{T}_{2}}{\partial t}=\frac{\partial}{\partial \mathrm{x}}\left(\mathrm{k}_{2} \frac{\partial \mathrm{T}_{2}}{\partial \mathrm{x}}\right)+0.239 j^{2} \mathrm{r}_{2}
$$

The subscripts correspond to the region, $\rho$ is the density $\left(\mathrm{gm}^{-3}\right), C$ is the heat capacity ( $\operatorname{cal} \mathrm{gm}^{-1}{ }^{\circ} \mathrm{K}^{-1}$ ), $\mathrm{T}$ is the temperature $\left({ }^{\circ} \mathrm{K}\right)$, $t$ is time (sec), $x$ is the position measured from the $U^{235}$ center line $(\mathrm{cm}), \mathrm{k}$ is the thermal conductivity ( $\mathrm{cal} \mathrm{sec}^{-1} \mathrm{~cm}^{-1}{ }^{\circ} \mathrm{K}^{-1}$ ), $j$ is the current density (amp $\mathrm{cm}^{-2}$ ), and $\mathrm{r}$ is the electrical resistivity $(\Omega \mathrm{cm}$ ).

The appropriate boundary conditions necessary for solving Eqns. (2) and (3) are

$$
\begin{aligned}
& \left.\frac{\partial \mathrm{T}_{1}}{\partial \mathrm{x}}\right|_{\mathrm{x}=0}=0 \\
& \left.\begin{array}{r}
\left.k_{1} \frac{\partial T_{1}}{\partial x}\right|_{\frac{L_{1}}{2}}-\left.k_{2} \frac{\partial T_{2}}{\partial x}\right|_{\frac{L_{1}}{2}}=0.239 \frac{\partial}{\partial t}(j \pi) \\
\left.2 k_{2} \frac{\partial T_{2}}{\partial x}\right|_{\left(L_{1} / 2\right)+L_{2}}=-0.239 \frac{\partial}{\partial t}(j \pi)
\end{array}\right\}
\end{aligned}
$$


where $\pi$ is the Peltier coefficient for the $n / p$ SiGe thermocouple (volts). The voltage per couple developed across the external load is equal to the Seebeck voltage minus the internal resistive voltage drop, i.e.,

$$
\mathrm{V}_{\text {Load }} / \mathrm{N}=\int_{\mathrm{T}_{2}\left(\frac{I_{1}}{2} \mathrm{~L}_{2}\right)}^{\mathrm{T}_{2}\left(\frac{\mathrm{L}_{1}}{2}\right)} \mathrm{s} \mathrm{dT}-2 j \int_{\frac{\mathrm{L}_{1}}{2}}^{\frac{\mathrm{L}_{1}}{2} \mathrm{~L}_{2}} r_{2} \mathrm{dx}-2 j \int_{0}^{\frac{\mathrm{L}_{1}}{2}} r_{1} d x
$$

where $S$ is the combined Seebeck coefficient for the $n / p$ Sige thermocouple.

Equations (1-5) form the complete set for determining the response of the device to a pulse of neutrons, $\varphi(t)$. The load voltage, $V_{\text {Load }}$, is of course related to the load current via response functions corresponding to the nature of the load, i.e., resistive, capacitive, or inductive. These equations are coupled and must be solved simultaneously.

\section{OPEN CIRCUIT EQUATIONS}

Since the purpose of this report is to examine the effects of material parameters on the device response we will consider only the open circuit case. The response of the device operating into different types of loads is the subject of a forthcoming report. For the open circuit case, $j=0$, and Eqns. (2-5) become

$$
\begin{aligned}
& \rho_{1} C_{1} \frac{\partial T_{1}}{\partial t}=\frac{\partial}{\partial x}\left(k_{1} \frac{\partial T_{1}}{\partial x}\right)+\dot{q} \\
& \rho_{2} C_{2} \frac{\partial T_{2}}{\partial t}=\frac{\partial}{\partial x}\left(k_{2} \frac{\partial T_{2}}{\partial x}\right)
\end{aligned}
$$




$$
\begin{aligned}
& \left.\frac{\partial T_{1}}{\partial x}\right|_{x=0}=0 \\
& \left.\frac{\partial \mathrm{T}_{2}}{\partial \mathrm{x}}\right|_{\left(\mathrm{L}_{1} / 2\right)+\mathrm{L}_{2}}=0 \\
& \left.k_{1} \frac{\partial \mathrm{T}_{1}}{\partial \mathrm{x}}\right|_{\frac{\mathrm{I}_{1}}{2}}=\left.\mathrm{k}_{2} \frac{\partial \mathrm{T}_{2}}{\partial \mathrm{x}}\right|_{\frac{I_{1}}{2}} \\
& V_{0 . C} / N=\int_{T_{2}\left[\left(I_{1} / 2\right)+I_{2}\right]}^{T_{2}\left(I_{1} / 2\right)} S d T
\end{aligned}
$$

Equations (6) and (7) and the boundary conditions [Eqn. (8)] may now be solved independently of Eqn. (9). Once the temperature distribution is determined the open circuit voltage may be calculated from Eqn. (9).

\section{CINDA ANAIYSIS}

The above equations are easily solved numerically using a numerical differencing code developed by the Chrysler Corporation called CINDA (Crysler Improved Numerical Differencing Analyzer). ${ }^{7}$ The approach is to divide the generator couple into thin sections and assign a node at the center of each section. The mass of the section is concentrated at the node and each node is connected by a conductance proportional to the thermal conductivity. This is illustrated in Fig. 3. The numerical solution is then generated by stepping the initial condition through a small time increment as defined by the differential equations for the particular node arrangement. Improved computational accuracy 
is obtained as the thickness of each section is reduced. In regions where the solution does not change rapidly with distance or time the section thickness may be increased without loss of accuracy.

In this report we are particularly interested in the speed of response to a pulse of neutrons. The open circuit voltage response has been investigated for a pulse of neutrons giving rise to heat generated in the U235 according to Eqn. (1) and with the time dependence shown in Fig. 4. This time dependence is completely arbitrary but will allow investigation of parameters which affect response of the fission heated couple. For purposes of the analysis we have assumed a standard couple with a thermoelectric element thickness of $0.0015 \mathrm{~cm}$ and a $U^{235}$ half-thickness of $0.0015 \mathrm{~cm}$. The thermoelectric elements are SiGe alloys (80 a/o $\mathrm{Si}$ ). The material properties used in the analysis are linear fits to compiled data. ${ }^{8}$

The details of the node network are illustrated in Fig. 5. Note that both the $U^{235}$ and SiGe are divided into two subsections. The subsections near the junction between the two materials are thinner and divided into a larger number of nodes since the temperature gradient is larger and changes faster in this region. The width of the subsections and the number of nodes were selected after allowing them to vary and inspecting the resulting solutions. Some contact resistance between the $U^{235}$ and SiGe has been incorporated into the solution since the response is affected by a poor thermal contact between the heat source $\left(U^{235}\right)$ and thermoelectric element. In the companion report describing the experimental testing of such a device, ${ }^{5}$ this contact resistance is attributed primarily to an intermediate material used to aid in bonding the $U^{235}$ and Sige together. The CINDA code for this analysis is given in the Appendix. 


\section{PARAMETRIC STUDY}

There are seven parameters that could affect the response of this device. These are the thickness, thermal conductivity, and product of density and heat capacity for both the $U^{235}$ and the thermoelectric material plus the interfacial thermal contact resistance between the $U^{235}$ and thermoelectric material. We can eliminate the thickness of the U235 and SiGe since the response is not a strong function of either thickness until they become of the order of 1 micron or less. This is seen in Fig. 6 which is a temperature distribution after 10 nanoseconds across the standard device described earlier. Since thicknesses less than 1 micron are not practical we will not investigate these two parameters.

If the fissionable material is restricted to $U^{235}$ then one might assume that the thermal conductivity and product of density and heat capacity is fixed. This is not necessarily true since bulk uranium may not be the best form to use. This is discussed in the companion experimental report. ${ }^{B}$ There thin films were investigated and they were not theoretical dense. Less than theoretical density affects the thermal conductivity but the product of density and heat capacity remains relatively constant. Thus the parameter associated with the fissionable material which affects the device response is the thermal conductivity.

We will investigate both thermal conductivity and the product of density and heat capacity for the thermoelectric material since a wide variety of thermoelectric materials are available for use. The list of parameters to be considered have now been reduced to four. The parametric analysis was performed by varying the standard device parameters individually. The standard device parameters are listed in Table I. 
Figure 7 illustrates the results of varying the thermal conductivity of the thermoelectric material. As the thermal conductivity is reduced the device produces more output voltage at a given time. This is due to the fact that the interface temperature between the thermoelectric material and uranium is maintained at a higher value due to less heat being conducted away through the thermoelectric material. A larger temperature gradient is produced across the thermoelectric material resulting in a large Seebeck voltage [see Eqn. (9)]. Thus the maximum voltage is produced when the heat conduction is zero and this is illustrated as the dotted line in Fig. 7 .

A similar effect is observed when the heat capacity (or product of density and heat capacity) is reduced in the thermoelectric material. This is seen in Fig. 8. For a given heat flow rate into the thermoelectric material, the rate of heating is faster for smaller heat capacities, i.e.,

$$
\frac{d q}{d t}=\rho V C \frac{d T}{d t}
$$

and hence a larger temperature gradient is produced.

The opposite effect results when the thermal conductivity of the fissionable material is reduced as shown in Fig. 9. In this case the interface is kept cooler by conducting heat away from the interface through the SiGe faster than it is conducted within the $U$ to the interface. The result is a lower temperature gradient across the thermoelectric material producing a lower Seebeck voltage.

As one would expect, the effect of reducing the interface thermal contact conductance is to slow down the response of the device (Fig. 10). The reason is, of course, that a larger temperature drop occurs across the contact for lower contact conductance. One basic difference is observed in the response as this parameter is varied. The output voltage does not peak at 
10 nanoseconds (peak of heat pulse) as it does when the other parameters are varied. A true lag in response is produced as a result of poor thermal contact.

\section{DISCUSSION}

The pulsed thermoelectric device can respond to a very fast pulse of neutron radiation. The output is improved by selecting a thermoelectric electric material which has a low thermal conductivity and a low product of density and heat capacity. In fact, the ideal response is obtained when the thermal conductivity approaches zero. This is in contrast to what has previously been suggested. ${ }^{3}$ The output is also improved if the thermal conductivity of the fissionable material is as large as possible. This implies that bulk $\mathrm{U}^{235}$ as opposed to less than theoretical dense thin films will probably be better even though thin films may be easier to produce. In spite of the fact that material properties different from optimum values are used, the device can still be designed to respond as fast as the incoming pulse of neutrons. This is seen by referring to Figs. 7-9. The peak output always occurs where the neutron pulse peaks. The reduced output can be compensated for by utilizing more fission couples.

The one parameter which causes a true lag in response is thermal contact resistance between the fissionable material and the thermoelectric material. Figure 10 shows that the peak output occurs at a time significantly later than the time of peak neutron flux as this contact resistance is increased. This is a factor which has been present in the experiments described in the companion report. ${ }^{5}$ However, with the proper development work, this factor could be eliminated. 
The purpose of this report has been to demonstrate theoretically that the pulsed thermoelectric device can respond to very fast inputs. We have considered only the open circuit response. Since the response is also a function of the electrical load, the load condition cases need also to be investigated. This will be the subject of a future report.

\section{Acknowledgment}

The author would like to express his appreciation to W. H. McCulloch for assisting with the CINDA analysis. 


\section{References}

1. D. B. Stillman and R. L. Chaney, Recent Advances in Fast-Response Miniature Neutron Flux Monitors, Los Alamos Scientific Laboratory Report IA4126, June 1969.

2. S. W. Angrist, Direct Energy Conversion (Allyn and Bacon, Inc., Boston, 1965), p. 127 .

3. S. E. Whitcomb, Sandia Laboratories Report SC-TM-273-61(5I), RS 513I/ 260, October 1961.

4. P. E. Gray, The Dynamical Behavior of Thermoelectric Devices (Technology Press, MIT, Boston, 1960), p. 58.

5. F. M. McIver and E. I. Burgess, Sandia Laboratories Report, SLA-740079, in preparation.

6. M. M. El-Wakil, Nuclear Power Engineering (McGraw Hill Book Company, Inc, New York, 1962), p. 188.

7. D. R. Lewis, J. D. Gaski, and I. R. Thompson, Chrysler Improved Numerical Differencing Analyzer for 3rd Generation Computers, Chrysler Corporation Space Division, New Orleans, TN-AP-67-287, October 1967.

8. A. Goldsmith, T. E. Waterman, and H. J. Hirschhom, Handbook of Thermophysical Properties of Solid Materials (Pergamon Press, New York, 1961), Vol. 1, p. 691; also, R. D. Nasby, Sandia Laboratories, unpublished. 
The CINDA code used for the analysis in this report. FDD, CM770R U, T320, EC1 . REQUESTER NAME

ACCOUNT CARD

FTN,T.

AT TACH, PRELIR, C. INDA, CY $=30$.

COLLECT, PROGRAM=PKEPRO, CI INFRU, PRELIR, FTNLIR.

CINPRO.

UNLOAR, CINPRO.

RFWINI, TADF] 3 .

FTN, I = TAPE $13, R=\prime, L=N O L I S T$.

UNL $\triangle A \cap, T A D E 13$.

ATTACH,RANLIR, CINDA, CY $=50$.

COLLECT,LGO,RANLIB,FTNLIB.

LGO.

COMMENT. ** *INDA JUB C JMPLETEO***

UNLOAD,LGO).

AT TACH,, TENLIP, CINDA, CY $=411$.

CULLFCT, DRUGRAM = T IMPLT, CINPLT, GFNLIR, FTNLI I , FXSCLRS.

RFL, โกกาก.

CINDIT

COMMFNT.

FXIT .

COMMENT.

RFWIND, NOL IST.

COPYRF, NOL IST, OUTPUT .

,

SUBROUTINE SERVUL (TEN, DELVI)

DIMENSION TFMII)

DELVI $=0$.

DO $\rightarrow(. \quad I=1,111$

$T \Delta V G=(T E M(1)+T F M(1+1)) * .5$

$S R \Delta R=.00 \cap 41 *\left(T A V r_{0}+773.1+.2\right.$ i ?

DFLV $=S R A R *(T F V(I)-T E U(I+1))$

DFLVI $=$ DFLVI+DFLV

IF(DFLV.LT.O.NUI) GO TO $1^{\circ}$

?O CONTINUF

10 RFTURN

END

NOT RECALL

ACD 3THFRMAL LPCS

DCD 8THIN FILM FAST RESPLNSF PULSED TIE DEVICE

FND

RCN 3NORF חATA

GEN $1,15,1,27,1,1,1,1,1,1$.

GEN 11,1n',1,27,,1,,1,,1,,1.

GEN $111,1,1,1,27,, 1,1,, 1,, ?$

GEN $211,1,, 1,27,1,1,1,, 1,1$.

GEN $221,6,1,27 \ldots, 1,1,1,1,-1$.

FNN

RCD 3CONDUCTOR DATA

DU REGIUN 1

DU REGIUN 2

\$SIGE REGIUN 3

ISIGE REGIUN 4

\$INTERFACE NOUES 
GEN $1,9,1,1,1,2,1,1,1,1,1,1$.

R.FN 10,99,1,11,1,12,1,1,1,1,1.1.

GFN $109,99,1,111,1,112,1,1,1,1,1$.

GEN $208,9,1,211,1,212,1,1 \ldots, 1 \ldots, 1 \ldots 1$.

RFM CONNFCT INTFPFACIAL NODFS

CGS 217,?? 1,1,A2,1.404F-5

CGC $218,17,222, A 2,1.404 E-5$

$\operatorname{CGS} 219,222,11, A 2,2.632 E-3$

CGS $22 U, 110,223, A 2,2.632 E-3$

CGS $221,223,224, A 4,1, F-9$

CGS $222,224,111, A 6,5.731 E-3$

CGS $223,210,225, A 6,5,731 E-3$

CGS $224,225,211, A 6,1.365 E-5$

CRC 275, ?70,?26,AG, $1.365 F-5$

FND

RCD 3CONSTANTS DATA

TIMFND, 15. ?, DT IMEI, .15, OUTPUT, I. NLOOP, 5C0, DRLXCA,.1) , ARLXCA,.01 TUPCON.273.16

$1,0,2,0,0,0,0,4,0$.

FND

RCN 2ARRAY DATA

1 SCP(CAL/GM-DEG) VS TEMP(C) FOR LURAIUM

$27 ., . \cup 26,527 \ldots, . \cup 41$, END

$2 \$ K(C A L / S E C-C M-D F G)$ VS TEMP(C) FOR UKANIUM

$27 \ldots, .36,527 \ldots, \ldots 7, F N D$

4 \$K (CAL/SEC-CM-DEG) VS TEMF(C) FOR IATERFACE

27., 1.F+5,5?7., 1 F +5, END

5 SCP(CAL/GM-DFG) VS TEMP(C) FOR SIGE

$27 ., 13,127 \ldots 145,277 \ldots, 155,477 \ldots, \ldots 1$, END

6 SK(CAL/SEC-CV-DFG) VS TEIAP(C) FUR SIGE

$27 ., 1122,527 \ldots, .01) 4$, END

7 SHEAT GENERATION(CAL/SEC-CC) VS TIME (NANOSEC)

$0 ., 0 ., 1 C ., 34.77,10.31011$, , END

४,TIME, TCNTLN, TU/INT, TINT/G, TSURF, VSEFB, ENJ \$LABEL AKRAY

10 \$THICKNFSSICM) OF U,SIRF

$.0015, . \cap \cap 15$, FND

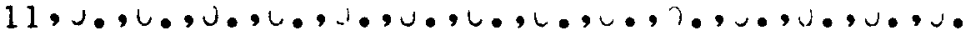

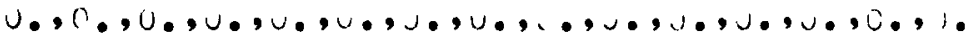

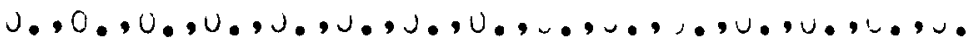

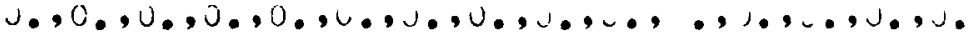

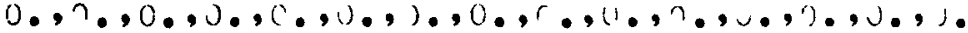

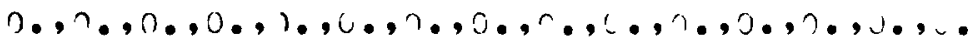

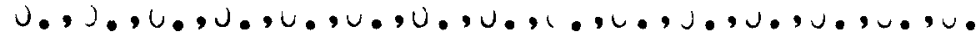

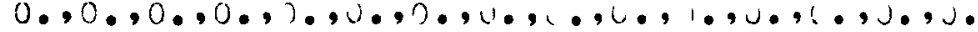

1), , , , , , , , , , , , , , , , , , , , , , , , , , .

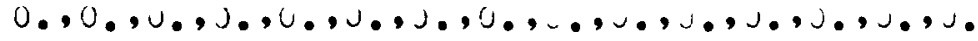

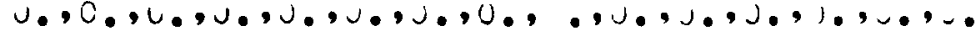

o, , , , , , , , , , , , , , , , , , , , , , , , , , , ,

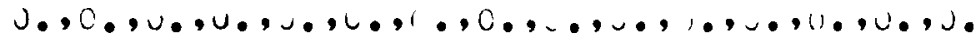

FND

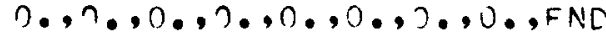

RCD 3EXECUTION

F

DIMENSION $\times(13 \cap 0)$
\$U REGION ? \$L RECIUN 2 DSIGE RFGIJA \& \$CIGE REGIUIV 4 


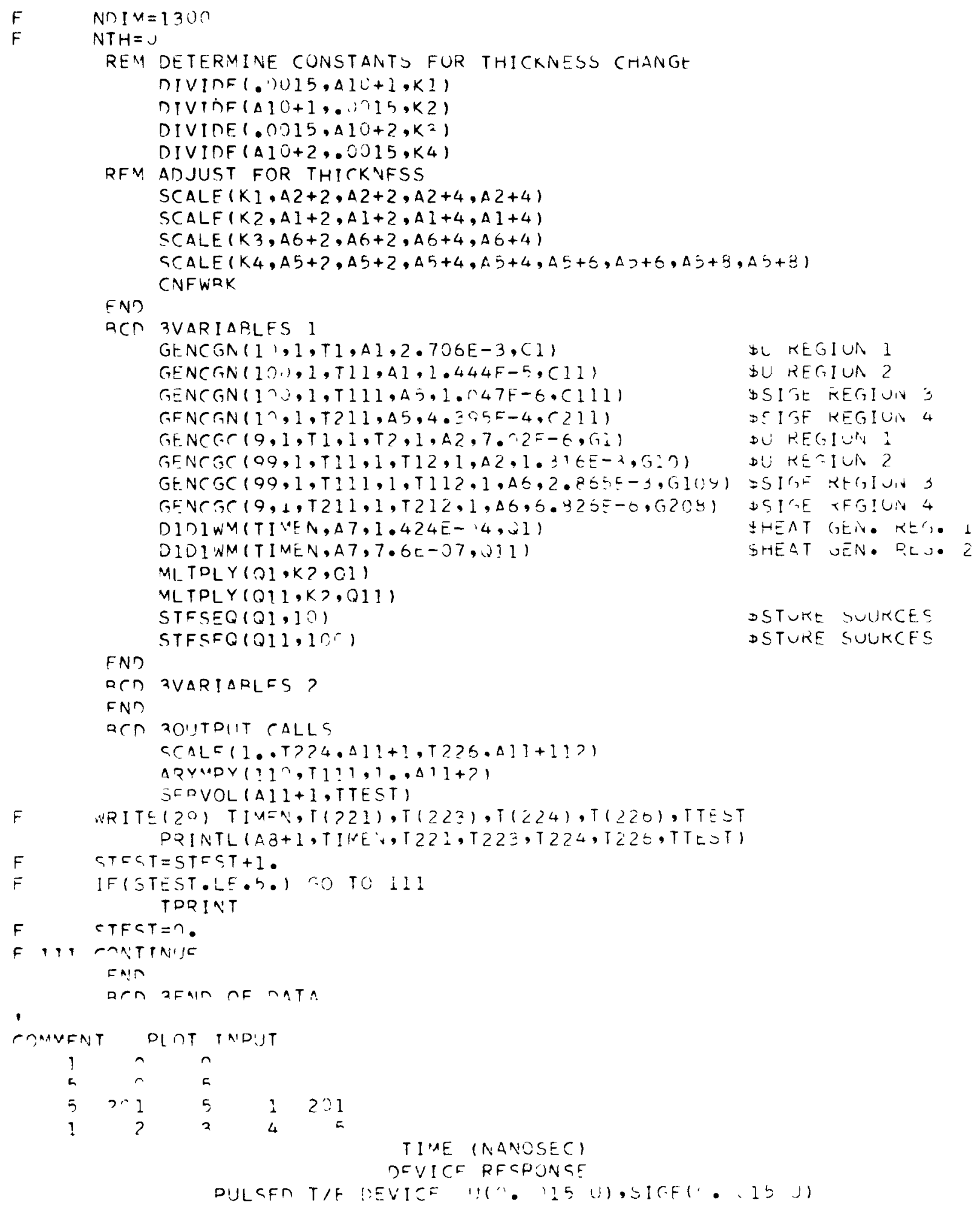




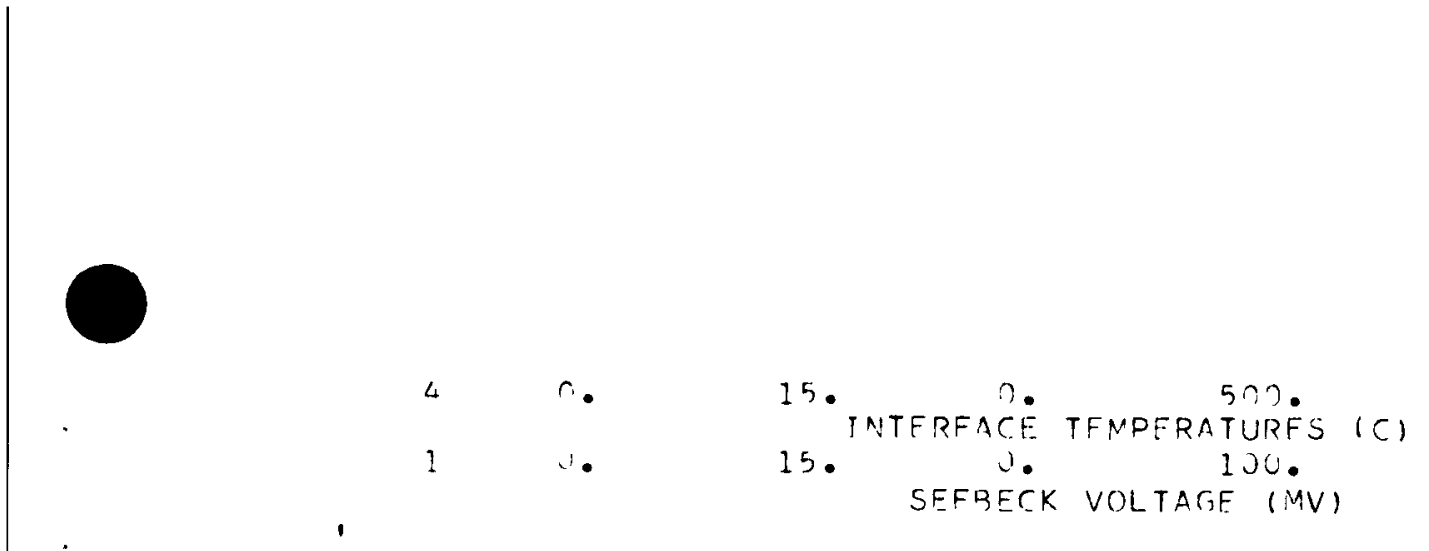


MATERIAL PARAMETERS USED FOR STANDARD PULSED DEVICE

\begin{tabular}{|c|c|c|c|}
\hline Parameter & Symbol & Value & Remarks \\
\hline Thermal Conductivity, SiGe & $\mathrm{k}_{\mathrm{SiGe}}$ & $\begin{array}{l}.0122 @ 27^{\circ} \mathrm{C} \\
.0104 @ 527^{\circ} \mathrm{C} \\
\left(\mathrm{col} \cdot \mathrm{sec}^{-1} \mathrm{~cm}^{-1} \mathrm{o}^{-1}\right)\end{array}$ & $\begin{array}{l}\text { Linear relationship between } \\
\text { the two temperatures }\end{array}$ \\
\hline Heat Capacity, SiGe & $\mathrm{C}_{\mathrm{SiGe}}$ & $\begin{array}{l}.13 @ 27^{\circ} \mathrm{C} \\
.145 @ 127^{\circ} \mathrm{C} \\
.155 @ 27^{\circ} \mathrm{C} \\
.161 @ 477^{\circ} \mathrm{C} \\
\left(\mathrm{cal} . \mathrm{gm}^{-1} \mathrm{o}^{-1}\right)\end{array}$ & $\begin{array}{l}\text { Linear relationship between } \\
\text { each pair of temperatures }\end{array}$ \\
\hline Density, SiGe & $\rho_{\mathrm{SiGe}}$ & $3.0\left(\mathrm{gm} \mathrm{cm}^{-3}\right)$ & $\begin{array}{l}\text { Assumed constant over temp- } \\
\text { erature range }\end{array}$ \\
\hline Thermal Conductivity, U235 & $\mathbf{k}_{\mathrm{u}}$ & $\begin{array}{l}.06 @ 27^{\circ} \mathrm{C} \\
.087 @ 527^{\circ} \mathrm{C} \\
\left(\mathrm{cal} \cdot \mathrm{sec}^{-1} \mathrm{~cm}^{-1} \mathrm{o}^{-1}\right)\end{array}$ & $\begin{array}{l}\text { Linear relationship between } \\
\text { the two temperatures }\end{array}$ \\
\hline Heat Capacity, U235 & $\mathrm{c}_{\mathrm{u}}$ & $\begin{array}{l}.026 @ 270 \mathrm{C} \\
.041 @ 527^{\circ} \mathrm{C} \\
\text { (cal. } \mathrm{gm}^{-1} \mathrm{o}^{-1}\end{array}$ & $\begin{array}{l}\text { Linear relationship between } \\
\text { the two temperatures }\end{array}$ \\
\hline Density, UR35 & $\rho_{\mathrm{u}}$ & $19.0\left(\mathrm{gm} \mathrm{cm}^{-3}\right)$ & $\begin{array}{l}\text { Assumed constant over temp- } \\
\text { erature range }\end{array}$ \\
\hline $\begin{array}{l}\text { Thermal Contact } \\
\text { Total Conductance }\end{array}$ & $\mathrm{K}_{\mathrm{C}}$ & $\begin{array}{l}1 \times 10^{5} \\
\left(\operatorname{cal} \cdot \sec ^{-1} \circ^{\circ} \mathrm{C}^{-1}\right)\end{array}$ & $\begin{array}{l}\text { Assumed constant over temp- } \\
\text { erature range. Value is equi- } \\
\text { valent to approximately } 1 \\
\text { micron gold } 1 \mathrm{~cm} \text { square. }\end{array}$ \\
\hline
\end{tabular}




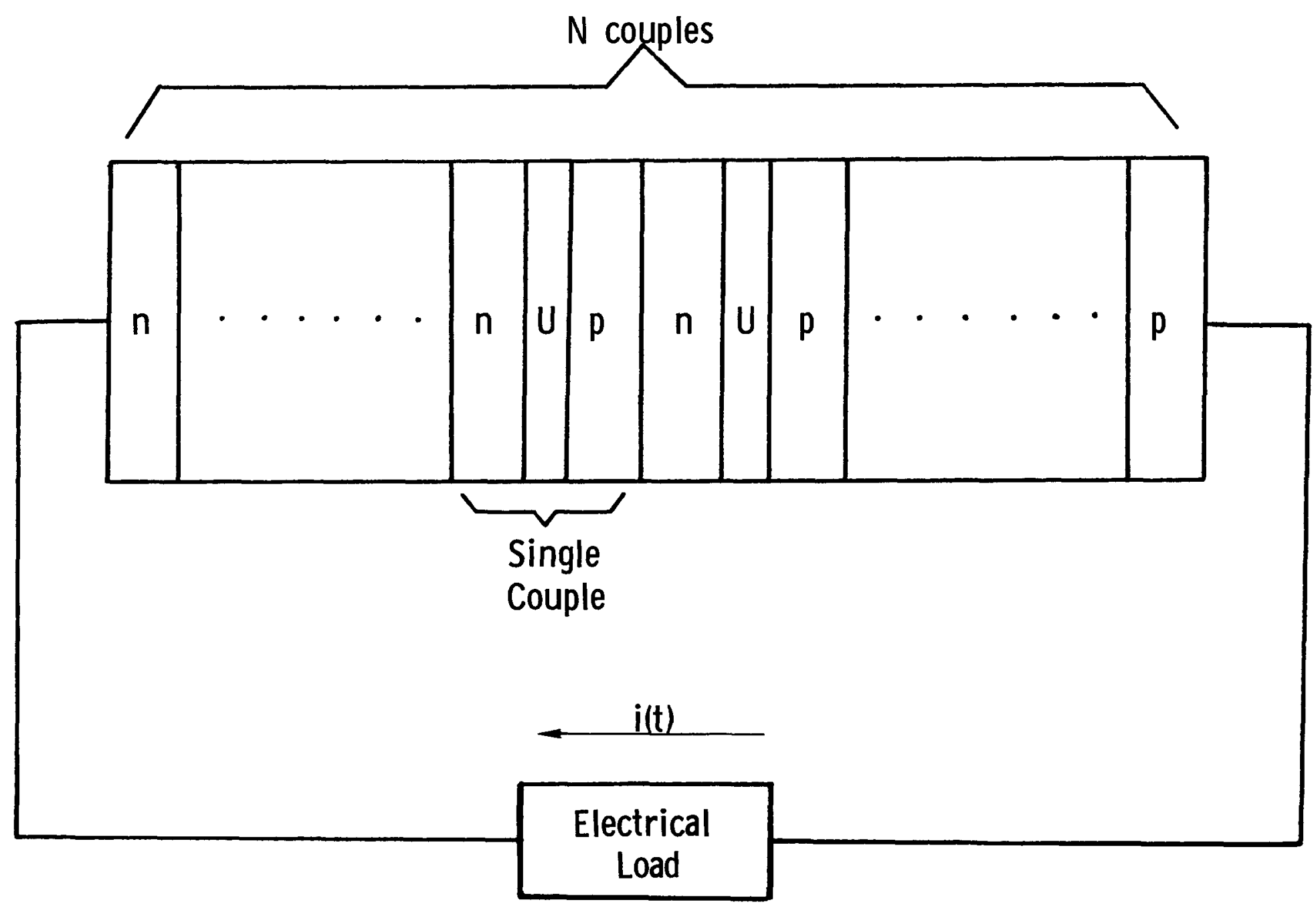

Figure 1. Schematic of pulsed thermoelectric generator. $n$ and $p$ are semiconductor thermoelectric materials and $U$ is uranium-235. 


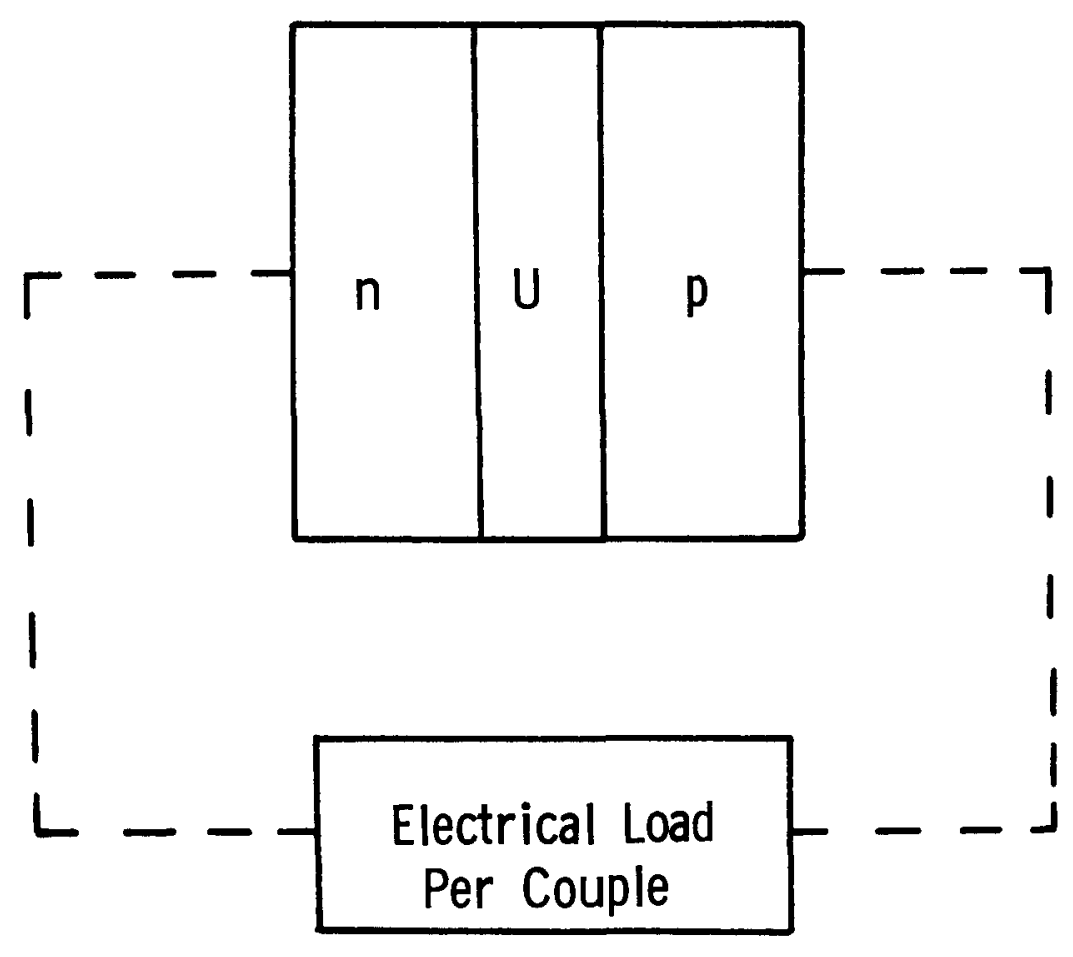

(a)

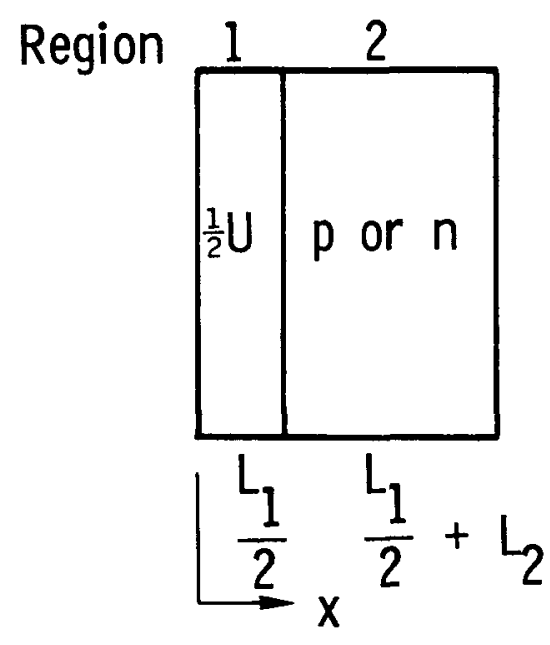

(b)

Figure 2. (a) Single fission thermocouple. (b) One-half couple used in symetrical heat transfer analysis. 


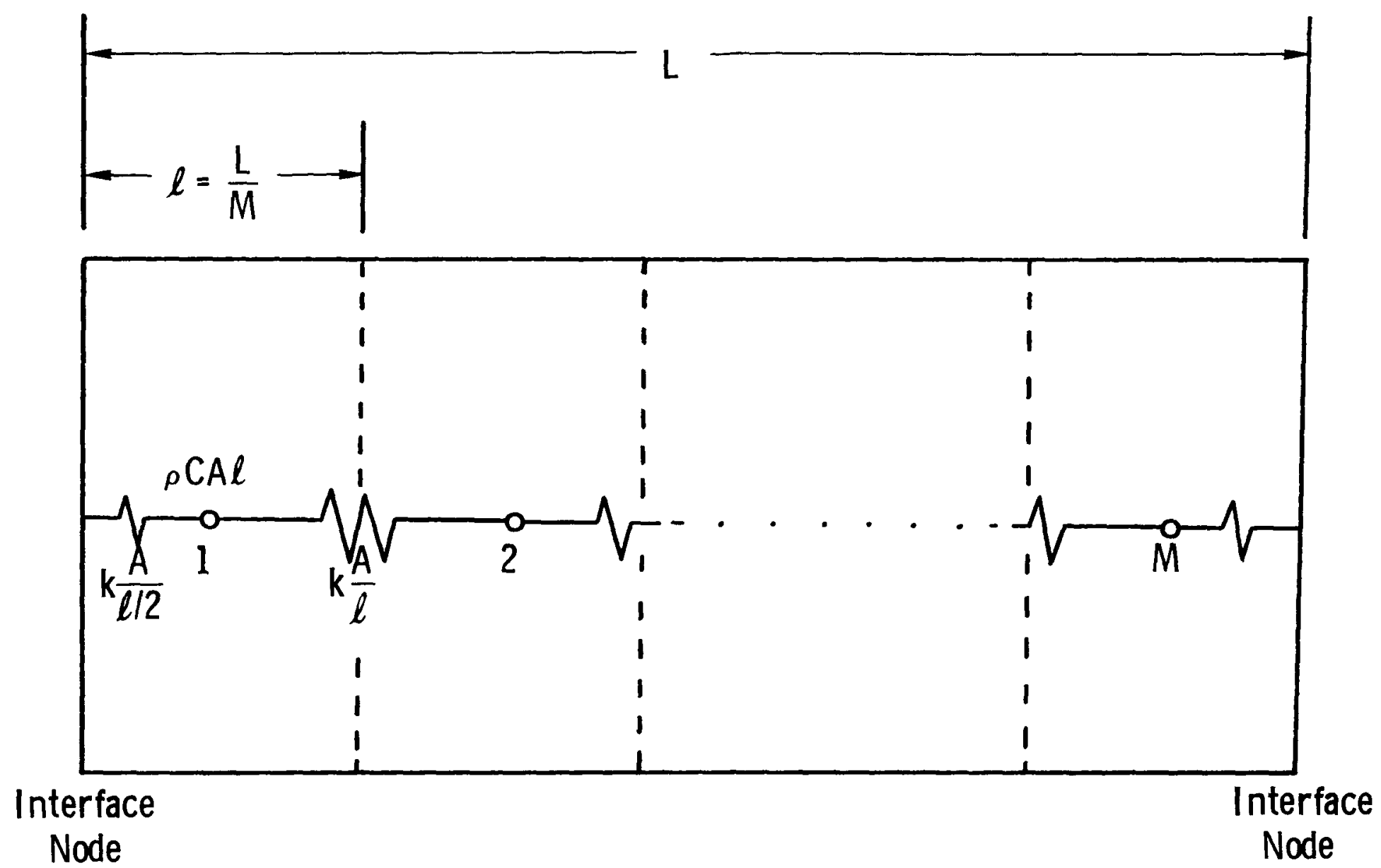

Figure 3. One-dimensional node arrangement for CINDA heat transfer analysis.

$L$ is length of element, $M$ is the number of nodes, $\rho$ the mass density, C the heat capacity, A the cross-sectional area, and $k$ the thermal conductivity. 


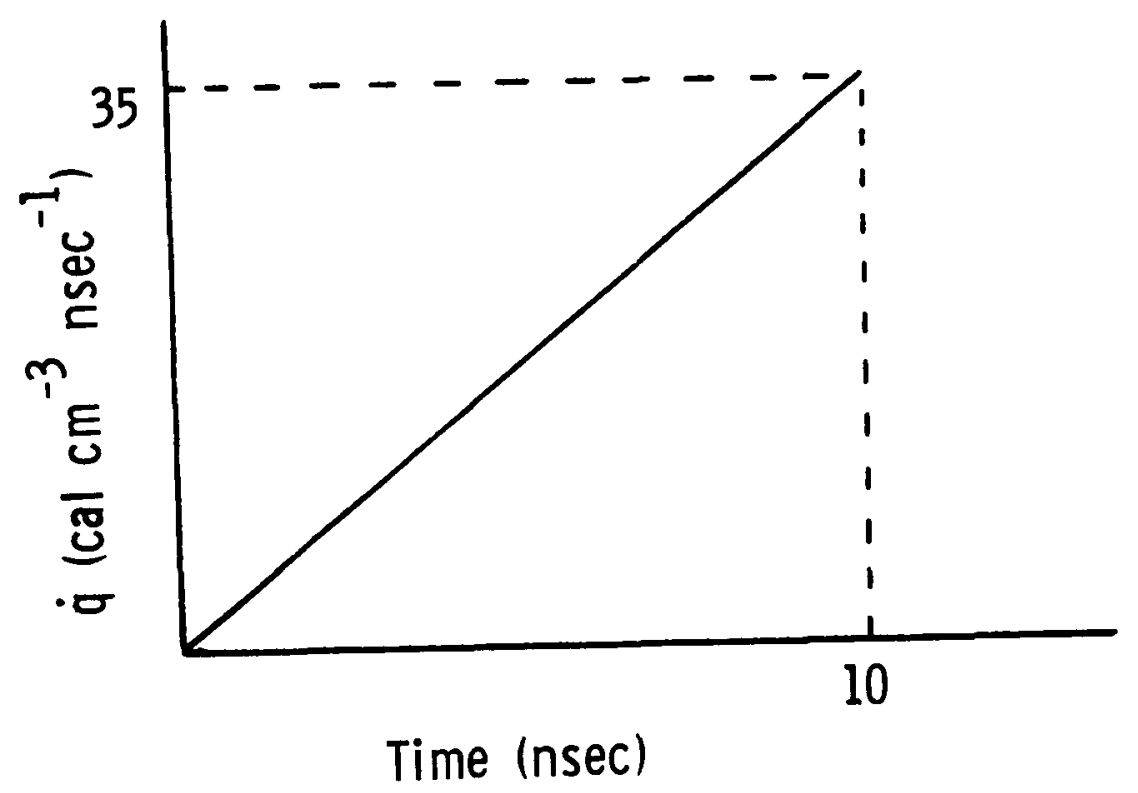

Figure 4. Heat generated in $U^{235}$ as result of arbitrary fast neutron pulse. This generated heat will produce a temperature rise of approximately $300^{\circ} \mathrm{C}$ in the $\mathrm{U}^{235}$. 


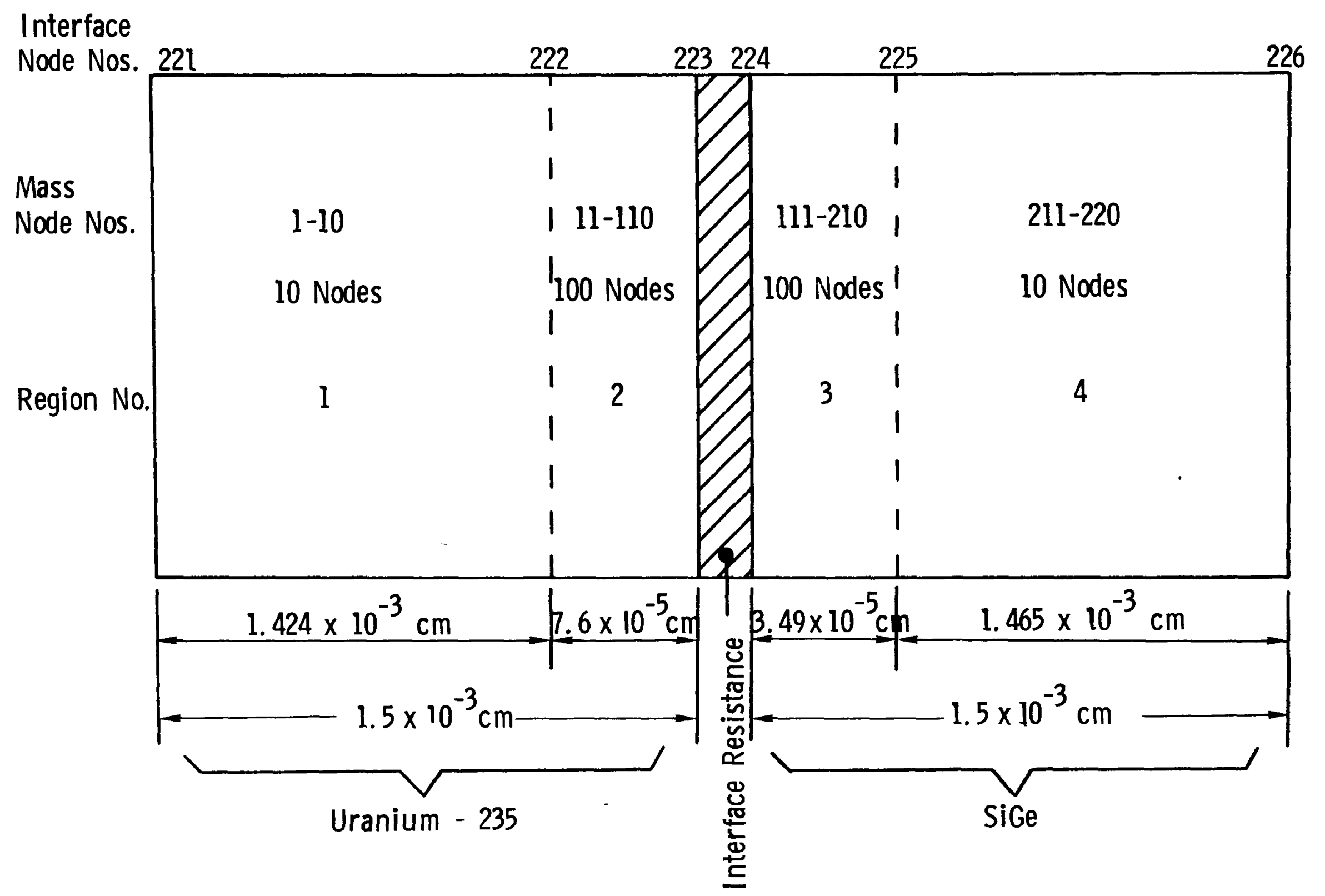




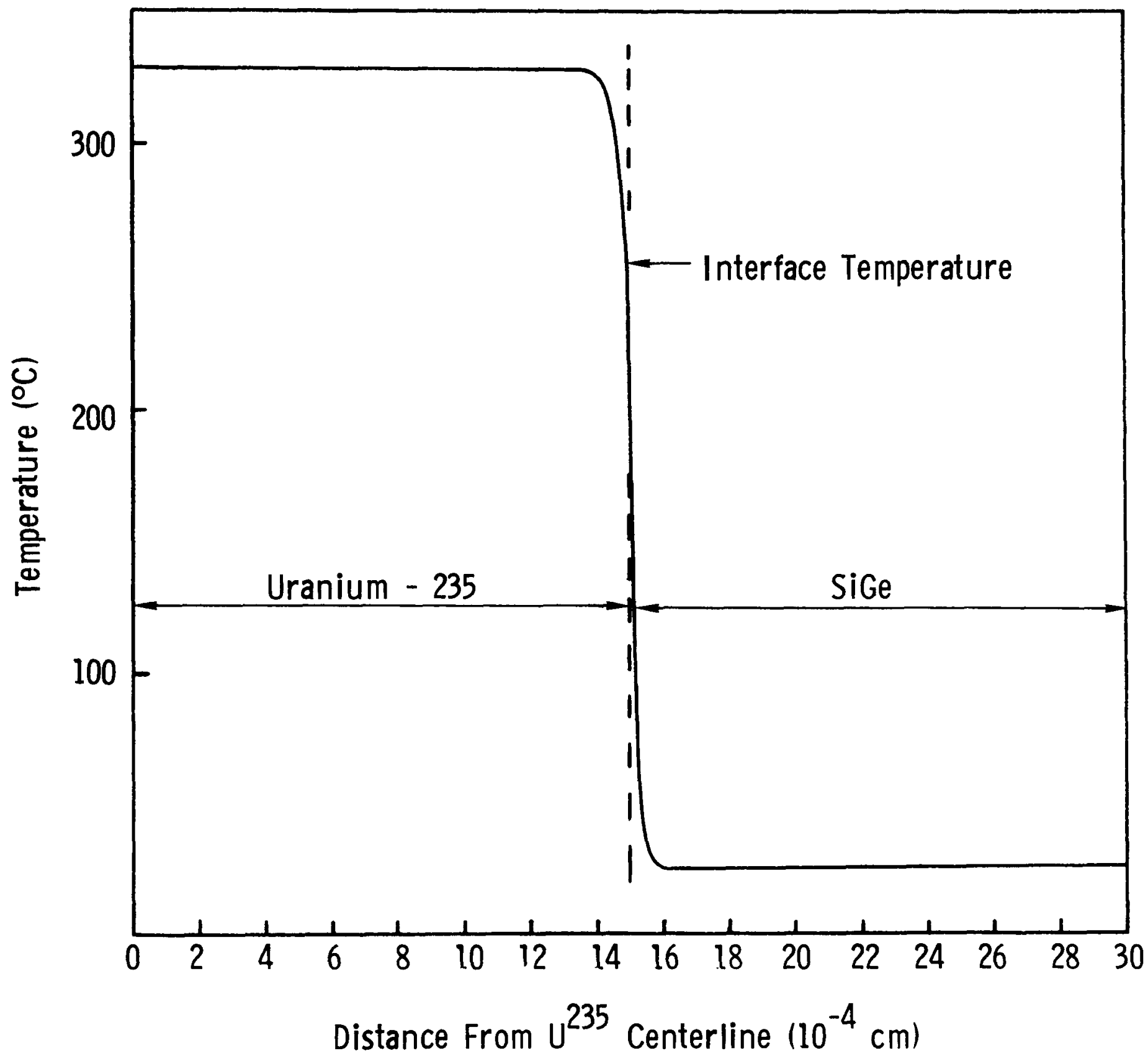

Figure 6. Temperature distribution across one-half couple of standard device after 10 nanoseconds. 


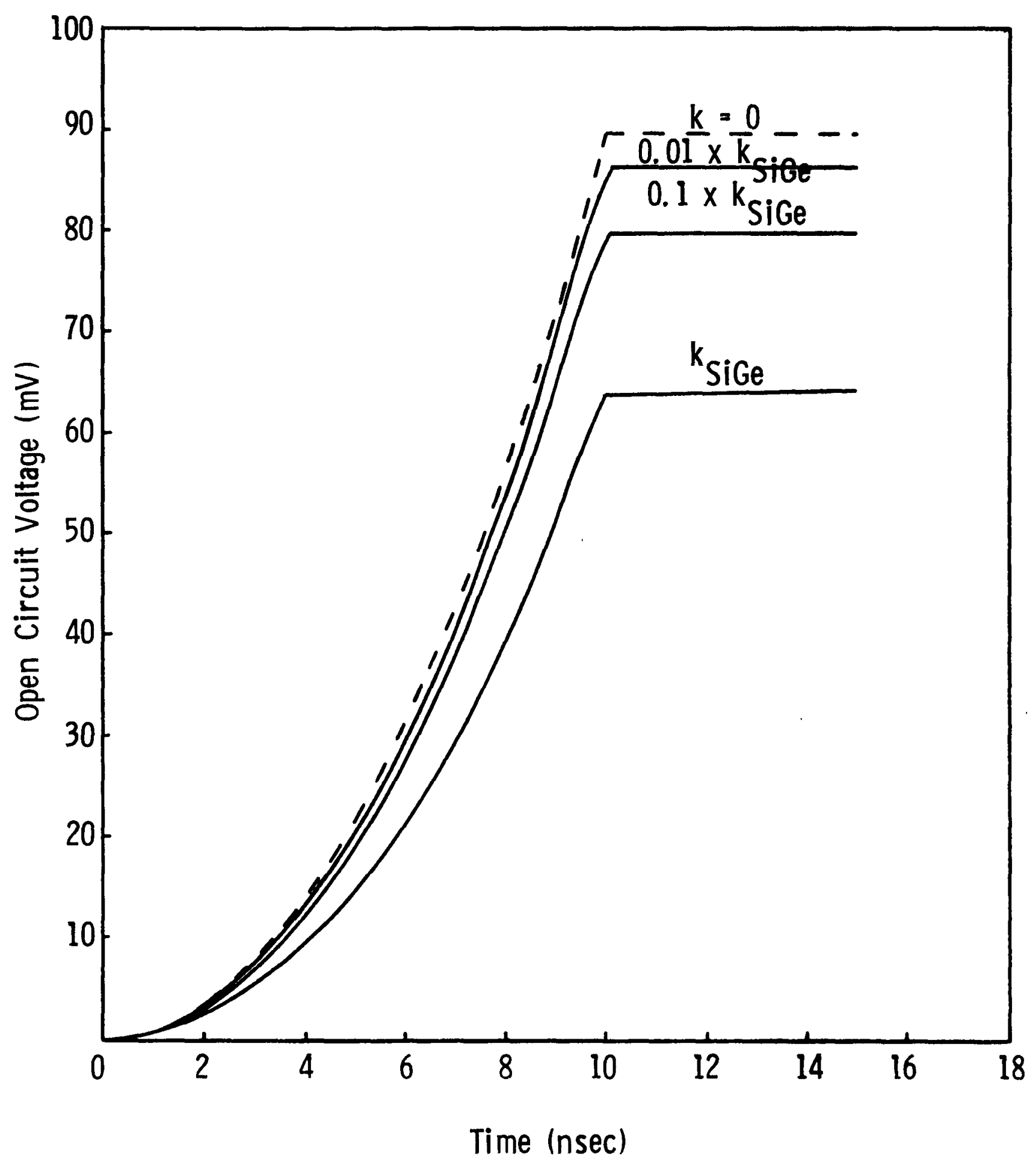

Figure 7. Response of device with thermoelectric material thermal conductivity as parameter. 


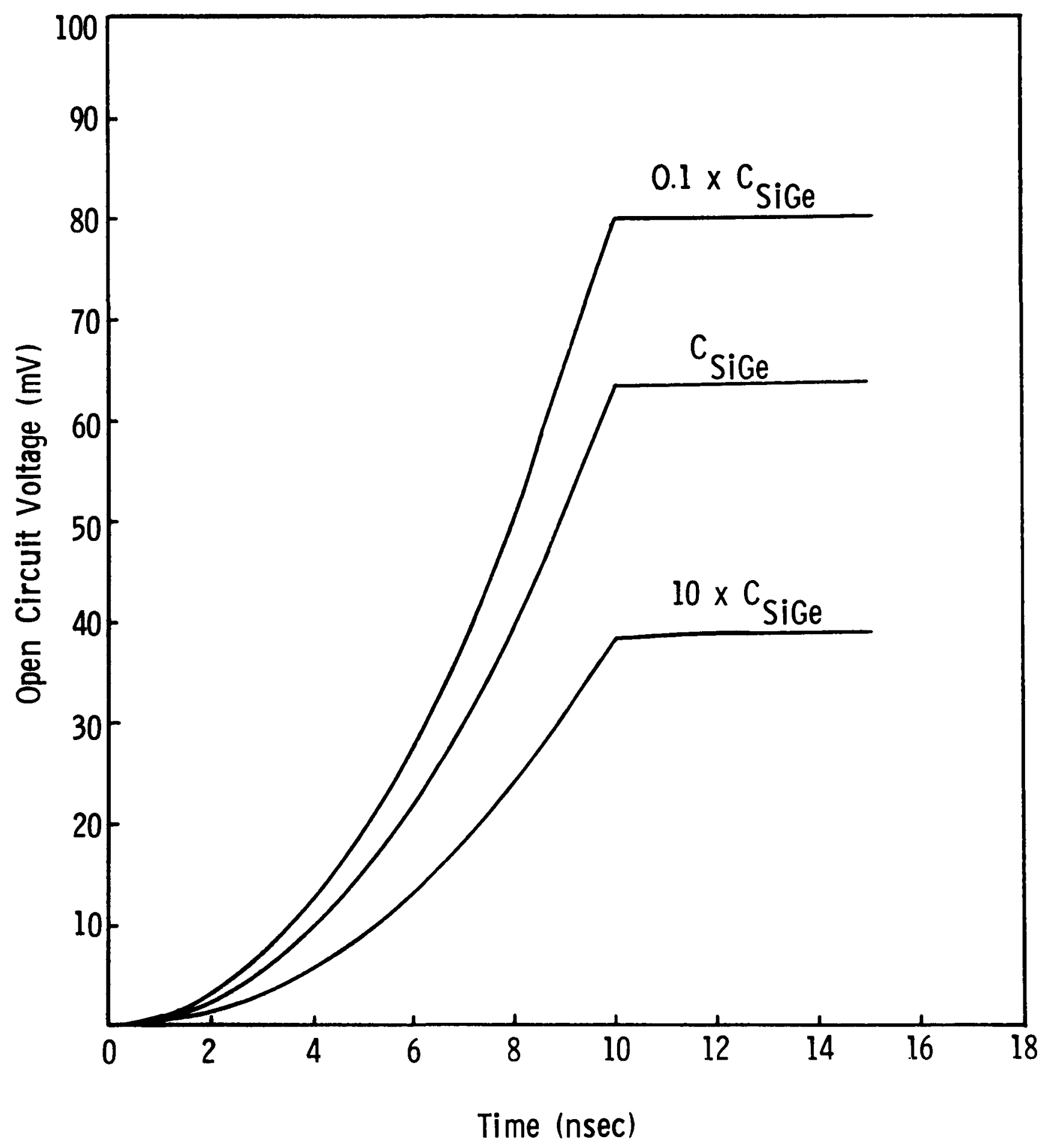

Figure 8. Response of device with thermoelectric material heat capacity as parameter. 


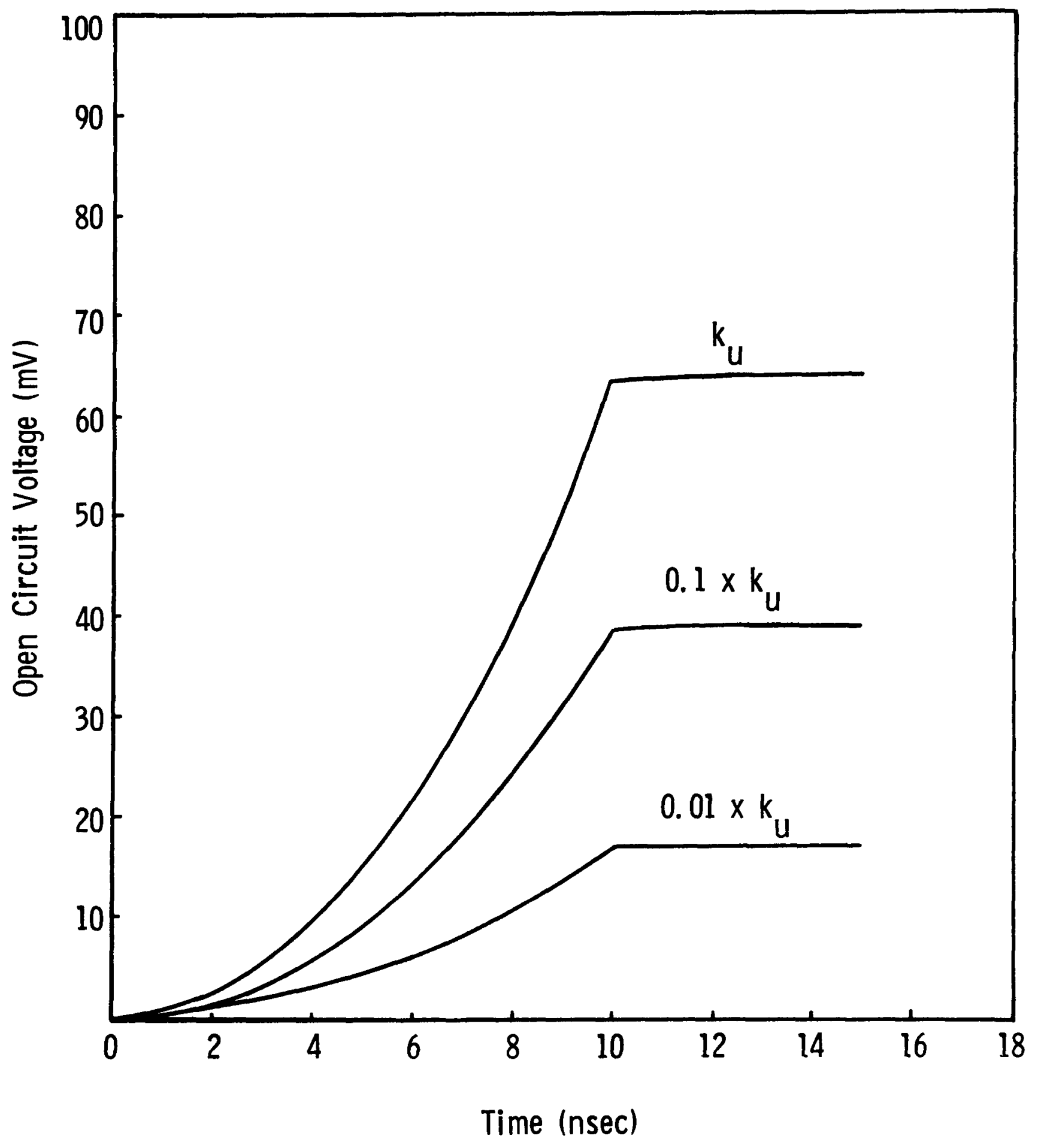

Figure 9. Response of device with fissionable material thermal conductivity as parameter. 
Distribution:

G. A. Fowler - 1000

Attn: C. D. Broyles - 1100

W. A. Gardner - 1200

H. E. Lenander - 1600

R. L. Peurifoy - 1500

Attn: D. M. Olson - 1510

G. J. Hildebrandt - 1520

C. H. Mauney - 1530

T. B. Land - 1540

W. H. McCulloch - 1543

A. W. Snyder - 1720

K. D. Bowers - 2000

Attn: W. J. Spencer - 2100

L. D. Smith - 2300

R. S. Claassen -2400

J. C. King - 2500

D. B. Shuster - 4700

R. G. Clem - 4730

J. M. Wiesen - 4750

A. Narath - 5000

Attn: E. H. Beckner -5200

A. Y. Pope - 5600

J. H. Scott - 5700

L. M. Berry - 5800

A. Narath (Actg.) -5100

Attn: F. L. Vook - 5110

G. J. Simmons - 5120

G. A. Samara - 5130

W. Herrmann - 5160

J. E. Schirber - 5150

Attn: A. C. Switendick - 5151

B. Morosin - 5154

J. R. Holland - 5157

R. T. Johnson - 5155

E. L. Burgess - 5155 (15)

J. H. S cott - 5700

L. Gutierrez - $8100 \mathrm{M} 0801$

Attn: A. N. Blackwe11 - 8110 M 0801

D. E. Gregson - 8150

R. Baroody - 8160

C. S. Selvage - 8180

E. A. Aas - 8266 (2) M 0801

A. M. Torneby - 3141 (5)

W. F. Carstens - 3151 (3)

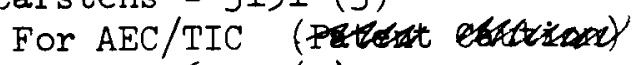

G. C. Newlin - 6011 (3) 